\title{
Obesity and long term functional outcomes following elective total hip replacement
}

\author{
Heather K Vincent, MaryBeth Horodyski, Peter Gearen, Richard Vlasak, Amanda N Seay, \\ Bryan P Conrad and Kevin R Vincent
}

\begin{abstract}
Introduction: Obesity rates continue to rise and more total hip arthroplasty procedures are being performed in progressively younger, obese patients. Hence, maintenance of long term physical function will become very important for quality of life, functional independence and hip prosthesis survival. Presently, there are no reviews of the long term efficacy of total hip arthroplasty on physical function. This review: 1) synopsized available data regarding obesity effects on long term functional outcomes after total hip arthroplasty, and 2) suggested future directions for research.

Methods: A literature search was conducted from 1965 to January of 2011 for studies that evaluated long term functional outcomes at one year or longer after THA in obese (body mass index values $\geq 30 \mathrm{~kg} / \mathrm{m}^{2}$ ) and non-obese patients (body mass index $<30 \mathrm{~kg} / \mathrm{m}^{2}$ ).

Results: Five retrospective studies and 18 prospective studies were identified as those that assessed physical function before surgery out to $\geq$ one year after total hip arthroplasty. Study sample sizes ranged from 108-18,968 and followed patients from one to twenty years. Total hip arthroplasty confers significant pain reduction and improvement in quality of life irrespective of body mass index. Functional improvement occurred after total hip arthroplasty among all studies, but obese patients generally did not attain the same level of physical function by the follow-up time point.
\end{abstract}

Discussion: Uncontrolled obesity after total hip arthroplasty is related to worsening of comorbidities and excessive health care costs over the long term. Aggressive and sustainable rehabilitation strategies that include physical exercise, psychosocial components and behavior modification may be highly useful in maximizing and maintaining weight loss after total hip arthroplasty.

Keywords: Arthroplasty, Body mass index, Hip, Physical function, Disability, Obesity

\section{Introduction}

The obese segment of the population with osteoarthritis is burgeoning, and the demand for total hip arthroplasty (THA) surgeries to treat obese persons is rising rapidly. Primary THA procedures will likely become necessary for a greater prevalence of the U.S. population who is developing debilitating OA earlier in life, and revision THAs will become more frequent as these young adults age and the life of the joint component ends. Evidence indicates that the relative risk ratio for undergoing elective hip replacement

\footnotetext{
* Correspondence: vincehk@ortho.ufl.edu
Interdisciplinary Center for Musculoskeletal Training and Research,

* Correspondence: vincehk@ortho.ufl.edu
Interdisciplinary Center for Musculoskeletal Training and Research, Department of Orthopaedics and Rehabilitation, Divisions of Research, Joint Reconstruction, \& Physical Medicine and Rehabilitation, University of Florida, Gainesville, FL 32611, USA
}

ranges from 1.92 in overweight individuals to 8.56 in severely obese individuals [1]. While extensive evidence has focused on surgical outcomes, mortality medical complications after hip replacement [2], the relationship between functional outcomes and obesity after THA over the long term is not well understood, particularly in the obese patient. This is a significant scientific deficit as restoration of physical function is one of the primary goals of THA [3,4].

As obesity rates continue rising and more THAs are being performed in progressively younger, obese patients, long term functional goals will become important. Functional goals may include maintaining independence with load bearing activities of daily living, independent mobility and body transfers over the long term. Many obese patients 
with THA will be recommended to perform exercise (heavy demand or weight bearing activity) for weight loss. In addition, progressively more obese patients with THA will be living longer with a joint implant and may be at risk for failure and poorer quality of life over the long duration compared with non-obese patients. For example, 35\% of patients with THA experience severe activity limitation by year five; obesity significantly predicted complete dependence on walking aids and is associated with depression at follow-up [5]. The physical component of quality of life is also lower in obese patients years after the procedure [6-8]. Hence, a clear understanding the effect of obesity on functional outcomes after THA will be critical in establishing expectations for the patients and care team and development of strategies to optimize physical function and independent mobility for as long as possible. Therefore, the purposes of this review are to: 1) provide a current synopsis of the available data regarding obesity effects on long term functional outcomes after THA, and 2) to suggest future directions for research.

\section{Search strategy}

We conducted a literature search from 1965 to January of 2011 in Medline, Cochrane Controlled Trials Register, CINAHL, Scopus and Web of Science. The search strategy identified studies in English that examined the relationships between obesity or BMI, physical function after total hip replacement. A functional measurement of mobility, ambulation or transfers or a comprehensive selfreport tool that assesses physical function had to have been reported a minimum of six months of follow-up after surgery. Estimates of obesity had to have been reported including body mass index (BMI), body fat percentage or fat mass. Medical subject headings (MeSH)/ keywords with all subheadings and as free text included obesity, obese, mobility, functional limitation, physical function, body fat, adiposity, waist circumference, total hip replacement and hip arthroplasty. Studies that administered surveys that reflected the perceived physical functional ability were also included; these tools included the Oxford Hip score (OHS), Harris Hip score (HHS), Western Ontario McMaster Osteoarthritis Index (WOMAC) score or other specially constructed surveys that included function-based questions, such as the University of California Los Angeles (UCLA) hip scoring system. Studies that used functional tests (walking tests, chair rise or timed up and go or body transfers or other self care tasks) were also included. A total of 552 papers were initially generated from this search. Studies that had a follow-up of less than six months, did not report any form of functional measure at follow-up or did not include an assessment of obesity were not included. The lists of references of retrieved publications were manually checked to add any citations missed by the electronic searches. Obesity was defined as an excessive body weight $>100 \mathrm{~kg}$, a BMI $\geq 30 \mathrm{~kg} / \mathrm{m}^{2}$ [9], or a large waist circumference ( $>88 \mathrm{~cm}$ women, $>102 \mathrm{~cm}$ men) [10].

\section{Characteristics of included studies}

A total of 23 articles were reviewed. Twenty articles included self-report assessments of the WOMAC, HHS or OHS or other survey based tools of physical function. Eight studies included objective physical function assessments. Studies were conducted in the United States [7,11-13], Europe (Netherlands [14], Scotland [15], the United Kingdom [6,16-19], Switzerland [3], Denmark [20]), Canada [2,21] and Australia [22-25]. Study sample sizes ranged from 140 [15] to 18,968 [3] and were comprised of $17-77 \%$ women, depending on the study. We identified three multicenter studies (two from Britain, one from Switzerland, and one with 7 to 20 sites) $[3,16,18]$ and two studies based on joint surgery registries (American-based registry study) [13] and a Canadian based registry [26].

Several studies demonstrated variability in the follow-up time points for assessment, which limits generalizability of the findings. For example, two retrospective studies captured follow up data from 0.1-15.6 years [14] and from 10-18.9 years [11]. Other retrospective studies captured follow-up times out to one year [2] or at different points of time during the years following the surgery $[7,11,24]$. A few prospective studies contained follow-up data from different time points during years following the procedure $[23,27]$.

\section{Hip surgical components and approaches}

Surgical technique, component type and use of cement varied among and within the identified studies. Several surgical techniques were used across the studies, including anterolateral $[6,14,16,19]$, posterior $[7,16,23]$, lateral [28] and posterolateral [11,20] approaches. There was also variation in the type of component used, and cement use for fixation of the component. Cement procedures were described in six studies $[6,7,14,15,29,30]$, and two studies described a mixed procedure of one cemented component and one non-cement component [28,31]. Numerous studies did not report or clearly describe the components or the surgical procedure $[2,3,13,15,17$ $19,22,24,26,29,32]$. Only a few of the studies controlled the number of surgeons performing the arthroplasties, thereby providing some control over the variation in the operating room procedures $[17,23,24]$. Therefore, the specific surgical details were widely varied among the study pool.

\section{Retrospective evidence}

We identified five retrospective studies, and the summaries of these studies are found in Table 1. Three 
Table 1 Retrospective studies of functional outcomes in obese and non-obese patients with total hip arthroplasty (THA)

\begin{tabular}{|c|c|c|c|c|}
\hline Study & N Follow-up & Sample & Surgical Type \& Components & Results \\
\hline $\begin{array}{l}\text { Braeken } \\
\text { et al [2] (1997) }\end{array}$ & $\begin{array}{l}193 \text { to } 1 \text { year; Retrospective } \\
\text { Mean age } 63.5 \text { years }\end{array}$ & $\begin{array}{l}61 \% \text { were women BMI was } \\
\text { found for each patient }\end{array}$ & $\begin{array}{l}\text { Surgical components not } \\
\text { described; surgical type not } \\
\text { described: data obtained from } \\
\text { medical charts and mailings }\end{array}$ & $\begin{array}{l}\text { While high BMI was related } \\
\text { to high postoperative pain } \\
\text { levels, BMI itself was not a } \\
\text { strong contributor to the } \\
\text { regression model for } \\
\text { WOMAC functional score } \\
\text { (parameter estimate value } \\
\text { of 0.092). }\end{array}$ \\
\hline
\end{tabular}

$\begin{array}{llll}\text { Haverkamp } & 411 \text { Mean out to } 20 \text { years; } & 69 \% \text { were women; BMl groups } & \text { Anterolateral approach; } \\ \text { et al [14] (2008) } & \text { Retrospective } & \text { were }<25, \geq 25 \mathrm{and}>30 \mathrm{~kg} / \mathrm{m}^{2} & \begin{array}{l}\text { Weber rotation THA System } \\ \text { Mean ages were } 64-66 \text { years }\end{array} \\ & & \text { (Allopro) with cement; }\end{array}$
among groups

$17 \%$ were women BMl groups were $<$ or $\geq 30 \mathrm{~kg} / \mathrm{m}^{2}$ Mean age 49 years
McLaughlin $28510-18$ years;

\& Lee [33] Retrospective
$51 \%$ were women; BMl groups were $<30$ or $\geq 30 \mathrm{~kg} / \mathrm{m}^{2}$ Mean ages 54-57 years

$53 \%$ were female; BMI groups were $<30$ or $\geq 30 \mathrm{~kg} / \mathrm{m}^{2}$
Posterior approach; 30-37\% of metaphyseal stem femoral components were cemented; Conserve Plus hip resurfacing prostheses were used

Uncemented T-tap acetabular components (Biomet Inc.) and Taperloc femoral points in obese patients and from 53 to components were used by one surgeon; all were posterolateral approaches

Cementless procedures used; components and approached were not described
HHS scores were progressively lower for higher BMI brackets at maximum follow-up time (91.6, 86.8 and 83.7 points; $p=0.02$ ); revision rates were similar among BMl complication rates and groups

By 6.2 years of follow-up, UCLA scores for function and activity werelower in the obese patients than non-obese patients by 8\%; SF-12 physical component scores were also lower in the obese group (49.3 vs 51.4 points; $p=0.013) ; 5$ year survivorship was $90.6 \%$ and $98.6 \%$ in patients with $\mathrm{BMl}<25$ and $30 \mathrm{~kg} / \mathrm{m}^{2}$, respectively.

By follow-up HHS $\uparrow$ from 52 to 8989 points in non-obese patients, with no difference between groups; no differences in revision rates or complications occurred between groups

HHS scores were lower for the obese compared to the non-obese patients at follow-up (89.9 vs 93.2 points; $\mathrm{p}<0.001$ ): HHS scores for function, activities, hip range of motion were lower in the obese group (all $p<0.05$ ); survival rates were for the implants were similar at year 11 (95-96\%)

THA = total hip arthroplasty; BMI = body mass index; EUROHIP = European Collaborative Database of Cost and Practice Patterns of Total Hip Replacement. $\mathrm{OR}=$ odds ratio; RR = relative risk; HHS = Harris Hip Score; UCLA = University of California and Los Angeles (UCLA) activity scale; Medical Outcomes SF-12 = Short Form 12; WOMAC = Western Ontario and McMaster Osteoarthritis Index; VAS = visual analogue scale. NS $=$ not specified.

studies evaluated obesity effects on HHS score values over varied follow-up time points out to 20 years. A BMI value of $>30 \mathrm{~kg} / \mathrm{m}^{2}$ was related with a $4-9 \%$ lower HHS scores at follow-up than BMI values less than $30 \mathrm{~kg} / \mathrm{m}^{2}[14,24]$. Despite HHS score differences, implant survival duration was similar by year 11 . One study that assessed follow-up HHS scores did not find differences in improvement levels between non-obese and obese patients after the procedure [11]. This corresponded with no differences in revision rates or medical complications. Two other reports showed that patients with higher BMI values had 4-9\% lower HHS scores at maximum follow-up time of $1-10$ years [14,24], and significantly less range of motion during hip flexion, adduction, internal rotation and lower knee flexion values than patients with normal BMI values. Similar to the findings of McLaughlin and Lee [11], Yeung et al [24] reported no differences in the probability of 11 year in implant survival based on BMI.

One study examined whether the functional and quality of life outcomes of hip resurfacing varied among nonobese and obese patients using data obtained from an institutional registry [7]. Data were obtained from clinical visits at four months, one year and annually after 
surgery, with follow-up times ranging from 2-10 years. In obese patients, post-operative HHS score were 3.2 points lower, UCLA sub-scores for "function" and "activity" were 4-7\% lower than those of the non-obese patients. UCLA sub-scores of "walking" were not different between groups. Interestingly, survival of the hip implant was higher in the obese patients compared to the non-obese patients by year 5 (98.6\% vs $90.6 \%)$.

\section{Prospective evidence}

Table 2 summarizes the prospective studies that we identified. Six studies used HHS as primary endpoints $[6,8,15,17,19,28]$, one study used OHS [16], one used the UCLA activity score [31], and six studies employed the WOMAC survey scores $[8,18,26,28,34,35]$ as a main outcome. Six studies used actual functional measures and patient reported functional abilities $[3,12,20,23,34,35]$.

\section{Harris hip score}

HHS scores and functional sub-scores were captured at a variety of time points ranging from one to five years. In one study, sub-scores of HHS were reported in nonobese and obese patients with THA by three years postsurgery [15]. Sub-scores of walking distance, climbing stairs, putting on shoes and socks, sitting and hip range of motion were $4-25 \%$ lower in the obese group at follow-up. Despite mean improvements in HHS and mobility, the cohort tended to gain weight by year three. Another study tracked functional and clinical outcomes in a group of morbidly obese patients with THA out to year five; HHS scores improved significantly in all patients by month six [6]. While the HHS scores were higher in non-obese patients by year five, the absolute improvement in scores were not different based on obesity status (52.0 vs 48.1 point change). Also, the morbidly obese patients had more peri-operative complications (12 vs 3 complications) and the five year survival was $90.9 \%$ and $100 \%$ in the obese and non-obese patients.

Both sex and revision status may be important factors influencing HHS outcomes. For example, HHS scores were evaluated among patients with a primary or revision THA in a Swiss cohort [28]. Patients with revisions had a relative risk of 1.67 for being obese, and BMI was found to be a stronger inverse predictor of HHS after revision procedures than primary procedures by year five. In a related study by the same author [8], HHS scores were collected in Swiss patients five years after THA procedures and found that $81 \%$ and $70 \%$ of non-obese and obese patients had good to excellent outcomes, defined as a HHS score $\geq 80$ points. These poorer outcomes were magnified in women than men. For example, HHS scores in non-obese and obese women were 87.8 and 79.6 points respectively, and were 90.5 and 87.4 points in non-obese and obese men.
Among predictive and correlational studies, Moran et al [19] examined whether BMI predicted HHS scores at follow-up times of six and 18 months post-THA. While no BMI-specific HHS data were presented, the authors reported a small but significant multiple regression coefficient for BMI on the model for the follow-ups HHS. This translated to a reduction in HHS by $0.25-0.35$ points per one point increase in BMI value. Another correlational study that we included did not report actual HHS scores, but superimposed HHS scores onto the Rosser Disability Index matrix to generate a "quality of life" score as a method of estimating functional disability [17]. The findings revealed that the median quality of life scores were not different among patients with low and high BMI values at one and three years of follow-up [17]. The authors concluded that progressively higher BMI values up to $40 \mathrm{~kg} /$ $\mathrm{m}^{2}$ were not related with these disability estimates.

\section{WOMAC scores}

One study examined the predictive value of one to four factors relating to the metabolic syndrome on WOMAC scores before and at one year after THA [26]. These factors included large waist circumference $(>102 \mathrm{~cm}$ men, $>88 \mathrm{~cm}$ women), elevated triglycerides and low high density lipoprotein cholesterol, high blood pressure and elevated fasting blood glucose. BMI was calculated for each patient. Regression analyses were performed to determine the effect of the number of metabolic syndrome factors on WOMAC scores by year one. The regression beta coefficient of having 4 metabolic factors on prediction of WOMAC scores was 16.1 in this obese patient group compared with the beta coefficient of 0.6 in non-obese patients with one factor. The coefficient for obesity alone was $2.4(\mathrm{p}=0.03)$.

A study that analyzed data from twelve European countries showed that one year WOMAC scores are related to BMI [18]. Median baseline WOMAC scores were higher in morbidly obese and obese patients compared with non-obese patients (68.1 and 61.5 vs 57.6 points) but the median change in WOMAC scores was highest in the morbidly obese group by year one (56.1 vs 33.3 and 37.5 points; $\mathrm{p}=0.012$ ). In this cohort, the multivariate odds ratio of returning to normal functional status was 3.1 compared to non-obese patients.

Lubbeke et al. performed two hospital-based cohorts examining the 1) five year outcomes in obese men and women with THA [8], and 2) the effects of comorbidities and age after primary and revision THA [28]. In the first study, sex differences in survey outcomes were analyzed in a cohort of patients with THA. The crude incidence rate was 4.7 times higher for infection, and the incidence rate was 2.3 times higher for dislocation in obese patients compared to non-obese patients. Five-year WOMAC function sub-scores were $11 \%$ lower in obese women than men and $8 \%$ lower in non-obese women than men. Within each sex 
Table 2 Prospective studies of functional outcomes in obese and non-obese patients with total hip arthroplasty (THA)

\begin{tabular}{|c|c|c|c|c|}
\hline Study & N Follow-up & Sample & $\begin{array}{l}\text { Surgical Type \& } \\
\text { Components }\end{array}$ & Results \\
\hline $\begin{array}{l}\text { Aderinto et al [15] } \\
\text { (2005) }\end{array}$ & $\begin{array}{l}1403 \text { years; Prospective } \\
\text { Follow-up }\end{array}$ & $\begin{array}{l}61 \% \text { were women; } \\
\text { groups were } \\
<30 \text { or } \geq 30 \mathrm{~kg} / \mathrm{m}^{2}\end{array}$ & $\begin{array}{l}\text { Cemented prostheses; } \\
\text { approaches or components } \\
\text { were not described }\end{array}$ & $\begin{array}{l}\text { At year } 3 \text {, HHS scores } \uparrow \text { from } 44 \text { to } \\
90 \text { points (non-obese) and from } \\
42.5 \text { to } 85 \text { points (obese), with no } \\
\text { difference between groups; lower } \\
\text { scores for stairs, sitting and putting on } \\
\text { shoes-socks and range of motion } \\
\text { were lower in the obese patients } \\
(p<0.05) \text {. }\end{array}$ \\
\hline
\end{tabular}

Andrew et al [16] 1,421 5 years; Multi-

(2008) center Prospective

Busato et al [3] (2008)

18,968 15 years; Multicenter prospective

Chan and Villar [17]

Chee et al [6]

(2010)

1085 years; Prospective cohort

Dowsey et al [29]

(2010)

4711 year; Prospective follow-up

Gandhi et al [26] (2010)

707 hips I year Prospective cohort
$62 \%$ were women; $\mathrm{BMl}$ groups were $<30,30-<40$ and $\geq 40 \mathrm{~kg} / \mathrm{m}^{2}$ Mean ages were $69.1,65.5$ and 60.6 years

sexes NS; BMI groups were $<25,25-<30$ and $\geq 30 \mathrm{~kg} / \mathrm{m}^{2}$

$59 \%$ were women BMI groups were $<25$, 25-29.9, 30-39.9, $>40 \mathrm{~kg} / \mathrm{m}^{2}$ Mean ages were $71.4,69.0$ and 68.1 years

$41 \%$ were women; BMI groups were $<35 \mathrm{~kg} / \mathrm{m}^{2}$ or $>35$ (1 comorbidity) and $>40 \mathrm{~kg} / \mathrm{m}^{2}$

$60 \%$ were women; BMI groups were $<30,30-39$ and $\geq 40.0 \mathrm{~kg} / \mathrm{m} 2$

59-66\% were women; waist circumference was assessed for metabolic syndrome BMI ranged from 22.0 to $36.6 \mathrm{~kg} / \mathrm{m}^{2}$ 64.8-66.2 years

77\% were women; BMl groups were Mean ages were 68 and 63 years
Anterolateral or posterior approaches were used; cemented Stryker Exeter femoral components and several different acetabular components

Surgical components not described; surgical type not described; Data were obtained from the Total Hip Registry (Switzerland)

Surgical components not described; surgical type not described

Anterolateral approach was used on all patients; $25.5 \%$ Charnley prosthesis (dePuy, Int.), 74.5\% Lubinus SPII prosthesis (Waldmar-Link $\mathrm{GmbH})$; cemented

Surgical procedures not described; surgical components not described; cement used varied across groups

Surgical components or procedures not described; patients were obtained from a registry

Posterior surgical approach; ABG2 Stryker cementless femoral and acetabular components
By year $5, \mathrm{OHS}$ scores were best in the non-obese group and worst in the obese group (19.6 vs 25.6 points; $p=0.005$ ), but no differences in the 5 year change in OHS scores existed. No differences in rates of revision, dislocations or medical complications existed.

High preoperative BMI was related with a dose-effect response with shorter unsupported walking time less normal stair climb, and shoe tying during the 15 year follow-up, despitesimilar pain relief across BMI brackets.

HHS scores were superimposed onto the Rosser Index Matrix (which ranks disability status); there were no differences in Rosser scores for disability among the BMl groups by year 3 .

Five year HHS were higher in non-obese than morbidly obese patients (91.8 vs 85.4 points; $\mathrm{p}<0.0001)$ despite similar preoperative scores; SF-36 subscores for physical functioning were lower in morbidly obese patients at year 5.

Morbidly obese patients had a lower change in HHS function scores than obese and non-obese patients, respectively by year 1 (11.5 vs 15.6 and 16.2 points, respectively); HHS were lowest in morbidly obese patients by year 1 (70.5 vs 79.8 and 80.8 points $p=0.03$ ).

1 year WOMAC scores (pain, function) were highest in patients with 4 metabolic syndrome factors compared to those with fewer factors; regression B coefficients showed that obesity predicted 1 year WOMAC scores $(B=2.4$ 1.4-4.2; $95 \% C l)$.

HHS were lower in obese vs non-obese patients at follow-up (89.9 vs 93.2 points); HHS functional scores were also lower in the obese group (29.6 vs 31.0 points); hip flexion, adduction and internal rotation ranges were less in the obese vs non-obese patients. HHS pain scores were not different between groups. 
Table 2 Prospective studies of functional outcomes in obese and non-obese patients with total hip arthroplasty (THA) (Continued)

\begin{tabular}{lll}
\hline Judge et al [18] & 1,3271 year EUROHIP & $56 \%$ were women; \\
(2010) & Study of 20 orthopedic & BMl groups were $<30$, \\
& centers & $30-39$ and $\geq 40 \mathrm{~kg} / \mathrm{m}^{2}$ \\
& Ages $<50$ to $\geq 70$ years
\end{tabular}

$\begin{array}{ll}\begin{array}{l}\text { Lubbeke et al [28] } \\ \text { (2007) }\end{array} & \text { 5-year; Prospective } \\ \text { cohort }\end{array}$

Lubbeke et al [8] (2007)

Lubbeke et al [30] (2008)

Lubbeke et al [31] (2010)
2,495 5-year; Prospective cohort
53-55\% are women; $\mathrm{BMl}$ groups were $<$ or $\geq 30 \mathrm{~kg} / \mathrm{m}^{2}$ Mean ages were 6872 years

48.7-57.5\% women; 8.5-9\% were revisions; BMl groups were $<$ or $\geq 30$ $\mathrm{kg} / \mathrm{m}^{2}$ Mean age 69 years

50-7.9\% were women; BMl groups were < or $\geq 30 \mathrm{~kg} / \mathrm{m}^{2}$ Age range $<50$ to $\geq 80$ years
Surgical components not described; surgical type not described

$85 \%$ of patients had mixed components (1 cemented,1 non)
Median WOMAC scores were highest in the morbidly obese group pre-THR, (68.1 vs 61.5 and 57.6 points).

but the 1 year change in WOMAC score was highest in the morbidly obese group (median score change of 56.1 vs 33.3 and 37.5 points); morbidly obese patients showed a $\uparrow$ OR of "returning to normal" (functionality) than the other groups.

Obesity was related with worse outcomes after revision than primary THA by year 5 (lower HHS scores: 76.7 vs 88.1 points; lower WOMAC function scores 61.6 vs 70.0 points). BMI was related to the mean difference of HHS scores for primary and revision $\mathrm{THA}$ ( $\mathrm{R}$ coefficient $=-1.0$

[-0.1 to $-1.95 \% \mathrm{Cl}]$ ).

95\% were lateral THA approach, $86 \%$ used Morscher press-fit uncemented actetabular component and Muller straight stem cobalt chromium femoral component

Cemented acetabular cups were used in $67 \%$ and $80 \%$ of obese and non-obese patients
$58 \%$ were women; BMI groups were $<25,25-29.9$ and $\geq 30 \mathrm{~kg} / \mathrm{m}^{2}$
Hybrid prosthesis; Morscher press fit uncemented cup and cemented cobalt-chromium stem (Zimmer); alumnia ceramic head, and a ceramicpolyethylene surface

All were anterolateral approach surgeries; components were not described

Surgical components not described; approaches not described
BMI of $\geq 30 \mathrm{~kg} / \mathrm{m}^{2}$ was related with a RR of 3.7-4.0 for revisions, 9.1-12.5 for dislocations and1.9-8.0 for infections in obese compared to non-obese men and women. By year 5, HHS were 87.8 and 79.6 points in nonobese and obese women and 90.5 vs 87.4 points in non-obese and obese men; WOMAC function scores were $14.7 \%$ and $8.0 \%$ lower in obese women and men thantheir non-obese counterparts.

HHS were $82.8 \pm 14.7$ and $71.4 \pm 17.0$ points in the non-obese and obese patients by year 5 . Surgical revisions were performed at 92 and 125 months in obese and non-obese groups, respectively. The adjusted hazard ratio for occurrence of infection, dislocation or re-revision increased from 1.0 $(\mathrm{BMl}<25)$ to 1.5 (BMl 25-29.9) to 4.5 (BMl 30-34.9) to 10.9 (BMI $\geq 35.0$ ).

At year $5, \mathrm{HHS} \downarrow$ with each rogressively higher BMI group (91.4, 88.4 and 85.1 points; $p=0.019$ ). At year 10, HHS tended to be lower in patients with $\mathrm{BMI} \geq 30 \mathrm{~kg} / \mathrm{m}^{2}$ compared with those with BMI $<25$ and $25-29.9 \mathrm{~kg} / \mathrm{m}^{2}$ (83.6 vs 87.3 and 87.1 points; $p=0.08$ ); more obese patients had low UCLA scores and more non-obese patients had higher UCLA scores.

For every 1 point increase in BMI, HHS scores dropped by 0.25 by month 6 and by 0.35 by month 18 post-surgery. No BMI effect on early failure of THA was found.

Obese patients had smaller increases in timed mobility than non-obese patients $(0.23 \mathrm{~m} / \mathrm{s}$ slower on $15 \mathrm{~m}$ walk time) and the timed up and go test (3.1 sec slower) at year 1; WOMAC scores for function and pain were worse in obese than non-obese patients by year 1 . 
Table 2 Prospective studies of functional outcomes in obese and non-obese patients with total hip arthroplasty (THA) (Continued)

Singh et al [12] (2009)
2,687 2-5 years; Prospective cohort of revision THA
53-54\% were women; BMI brackets were $<25$, 25-29.9, 30-39.9 $\geq 40 \mathrm{~kg} / \mathrm{m}^{2}$ Mean 5 year age was 65 years
Surgical components not described; approaches not described

At year 2, the OR for complete dependence onwalking/gait aids was 2.0 (vs 0.9 for BMI 25-29.9); moderate to severe activity limitation was predicted by high BMI. The OR of reporting difficulty in 3 of 7 mobility and functional tasks $\uparrow$ from 1.2 to 2.7 with increased BMI from 25-29.9 to $40 \mathrm{~kg} / \mathrm{m}^{2}$, by year five, the OR increased to 1.3 and 3.0 in these same BMI brackets (all $p<0.01$ ).

Søballe et al (1987) 1255 years;

[20] Prospective follow-up

Stickles et al [13] (2001)

\section{1 year; Prospective} follow-up
A weight index was calculated as < or $>120 \%$ of pre-surgical weight; analyses were also performed using weight brackets of $<$ or $>80$ kg; Mean age at follow-up 70 (28-89) years

$56 \%$ were women; $\mathrm{BMl}$ brackets were $<25$, $25-29.9,30-40>40 \mathrm{~kg} / \mathrm{m}^{2}$ Mean age 69 years
All were posterolateral approach surgeries; Lubinus prostheses were used and fixed with gentamicin impregnated radiopaque PMMA; One surgeon performed all hip replacements

Surgical components or procedures not described; patients were obtained from a registry
Walking ability, defined using the Charnley scoring system was lower in patients with a weight index $>120$ pre-surgery, but similar to patients with indexes $<120$ by year 5 (4.9 vs 5.0 points; $p=$ NSig).

By year 1, stair ascension and descension difficulty was reported in $86-88 \%$ of very obese patients compared with $46-55 \%$ of non-obese patients; BMI did not correlate with change in WOMAC scores (31.8 and 35.9 points, in non-obese and very obese patients, respectively; $p>0.05)$

THA = total hip arthroplasty; BMI = body mass index; EUROHIP = European Collaborative Database of Cost and Practice Patterns of Total Hip Replacement. $\mathrm{OR}=$ odds ratio; RR = relative risk; HHS = Harris Hip Score; UCLA = University of California and Los Angeles (UCLA) activity scale; Medical Outcomes SF-12 = Short Form 12; WOMAC = Western Ontario and McMaster Osteoarthritis Index; VAS = visual analogue scale.

$\mathrm{NSig}=$ non-significant.

group, obese women and men had 8-11\% lower WOMAC function sub-scores than their non-obese counterparts. In the second study, patients with primary and revision procedures were administered the WOMAC at five years [28]. of note, the patients with revisions were more often obese than not. The WOMAC function sub-score was reported to be lower in obese patients with revision THA compared with non-obese patients (61.6 vs 70.0 points). This difference was deemed small but clinically significant.

A sample of Australian patients with primary unilateral THA was analyzed for differences in WOMAC responses by year one [34]. The obese patients reported improvements in WOMAC function subscores from 44.6 to 23.3 points while the non-obese patients demonstrated improvements in this same subscore from 40.7 to 13.7 points. Hence, the non-obese patients showed a greater relative functional improvement than obese patients at year one. Stickles et al [35] prospectively assessed WOMAC responses in persons with THA across the BMI spectrum: $<25,25-20,30-35,35-40$ and $>40 \mathrm{~kg} / \mathrm{m}^{2}$. At one year after surgery, WOMAC scores were progressively less with each higher BMI bracket. There were no differences among BMI brackets in the total complication rate, medical complication rate or orthopedic complication rate.

\section{Oxford hip scores (OHS)}

One study presented responses to the Oxford Hip survey in groups with low and high BMIs. Andrew et al. [16]. compared the OHS in non-obese, obese and morbidly obese patients pre-surgery, three months and annually until year five. By year three, the average OHS was highest in the non-obese group and lowest in the morbidly obese group ( $19.6 \pm 8.6$ vs $23.5 \pm 11.4$ points); this pattern was maintained out to year five. However, the five year change in absolute OHS was not different based on BMI, indicating comparable responsiveness to the procedure over the long term. There were no differences in the rates of perisurgical medical complications or long term femoral stem position, femoral osteolysis or implant survival.

\section{UCLA activity score}

A prospective study that compared the osteolysis rates and patient satisfaction after THA was conducted by Lubbeke et al [31]. The patient activity level was assessed using the UCLA survey at the pre-surgery time point and at years five and ten after THA. Patients were stratified into non-obese, overweight, and obese groups based on BMI. While the mean UCLA scores were similar between groups at follow-up, the $6.8 \%$ of obese patients 
achieved a high activity UCLA score compared to $11.7 \%$ overweight and $14.4 \%$ of normal weight groups. This finding was corroborated with lower follow-up HHS in the obese group compared to the remaining groups. Obese patients had poorer pain scores and an odds ratio of 1.44 of developing femoral osteolysis whereas the normal weight had an odds ratio of 2.64 compared to the reference overweight group.

\section{Functional tests}

Several studies assessed functional capacity with walking tests, stair climbing, and timed functional tests. In an early study, walking ability was a primary functional five year endpoint for a Danish cohort of patients with THA [20]. Radiographic and surgical outcomes were measured in addition to walking ability. The Charnley criteria [36] were applied to walking ability (6 points $=$ walking, no limp; 5 points = extensive walking, with or without cane, with limp; 4 points = moderate walking with one crutch or cane; 3 points $=$ restricted walking with crutches; 2 points $=$ wheelchair transfer activity; 1 point $=$ bedridden) before and after THA. Patients were stratified based on a weight index $(<$ or $>120 \%$ of normal weight for height and sex) or by body weight $(<80 \mathrm{~kg}$ or $>80 \mathrm{~kg}$ ). Pre-operatively, walking ability scores were different based on $\%$ of normal weight (1.8 vs 2.3 points in heavy versus non-heavy patients, respectively; $\mathrm{p}<0.05)$ but not absolute body weight ( 2.2 points for both groups). Five years post-THA, Charnely walking scores were not different based on either expression of body size. While surgical blood loss was greater in heavy patients compared with non-heavy patients, there were no significant differences in operation time, medical complications or loosening of the implant based on weight.

Naylor et al [34] in Australia, performed short functional tests in obese and non-obese patients before and at various time points out to year one. These tests included a 15meter walking test and a timed-up-and-go (TUG) test where an individual rises from a chair and returns to the chair. While obesity did not preclude improvement in 15 meter walking speed, the trajectory of change was lower in the obese group by year one, and final walking speeds were $1.37 \mathrm{~m} / \mathrm{s}$ and $1.14 \mathrm{~m} / \mathrm{s}$ in non-obese and obese patients, respectively. Similarly, improvements in TUG test time were slower in the obese group by year one (final TUG times were $9.2 \mathrm{sec}$ and $12.4 \mathrm{sec}$ in the non-obese and obese patients). The approximate $30 \%$ an $42 \%$ improvements in walk and TUG times were not different based on obesity status. There was a $2.8 \%$ greater chance that obese patients would use a walking aid at follow-up compared to nonobese counterparts.

Difficulty ascending and descending stairs was one endpoint in a prospective study of American patients hip or knee arthroplasty [35]. Among the patients with THA, and it was shown that the percentage of patients in each progressively higher BMI bracket $(<25$ to $>40 \mathrm{~kg} / \mathrm{m} \mathrm{[2])}$ reported difficulty with descending and ascending stairs. This functional pattern was corroborated with self-report WOMAC data, which showed lower scores in the one year total WOMAC score and related physical component subscore in severely obese patients compared to non-obese patients. Total medical complication rate was not different across the BMI spectrum. However, a major limitation to the study was that the specific technique used to capture this stair climbing information was not presented in the methods.

In a cohort of American patients with revision THA, activity limitation and dependence on walking aids was assessed by Singh et al [12] at years two and five postTHA. The evidence revealed that the odds ratio of developing moderate-severe physical activity limitation increased from 1.2 to 2.7 in overweight and morbidly obese patients. Severe obesity increased the two and five year odds ratios of developing complete dependence on walking aids to 2.0 and 2.7 compared with the reference of normal weight.

Busato et al [3] collected a series of functional measurements in a cohort of Swiss patients with THA at periodic follow-ups, including walking distance without support, hip flexion range, stair climbing and putting on shoes and socks. Data were reported as the percent of patients who were able to achieve walking $>60$ minutes, hip flexion range $>90$ and capacity for normal stair climb and donning of footwear. Irrespective of time point, fewer obese patients were able to walk $>60$ minutes without support and this percentage continued to lowered $27.2 \%$ from year three to year 12 compared with the $18.5 \%$ fewer non-obese patients. This same pattern occurred with stair climbing and with tying shoes by year 12 . Interestingly, the obese patients increased the hip flexion range of motion by $7.8 \%$, whereas the non-obese group lost $11.6 \%$ of hip flexion motion by year 12 . In all three BMI strata, pain relief was achieved in the majority of patients and was largely maintained by year 12 .

Hip range of motion was assessed in non-obese and obese patients with cementless THA at a median followup time of 5.1 years in addition to pain ratings, survey scores and implant survival. Despite equivalent implant survival rates between groups, obese patients achieved 9.4 less range of movement about the hip than nonobese patients with flexion, 2 less adduction and 2.8 less of internal rotation. Interestingly, pain relief and patient satisfaction with the procedure were similar between groups at follow-up.

\section{Overview of the findings}

Of the evidence included in this review, the surgical component, cementation or surgical approach did not 
appear to have any consistent effect on long term functional outcomes in the obese patient. Of the 23 studies, 16 reported that obesity was associated with lower hip function survey scores at follow-up, whereas four studies did not. Five studies revealed negative long term effects of obesity on various tasks of physical function, and one study noted no adverse influence of obesity on walking ability. While obesity does not necessarily preclude functional improvements after surgery, the functional gains achieved and the self-reported functional ability generally are lower than those attained by non-obese patients. Thus, evidence indicates that there is significant pain relief and patient satisfaction after THA in obese patients, whereas these patients fall short of achieving the same long term functional level as their non-obese counterparts. Hence, in a time frame of as short as one year after THA, obese patients are already at a functional deficit compared to non-obese counterparts.

\section{Potential explanations for functional outcomes in the obese patient}

Some postulated mechanisms underlying this finding include fear of movement and fear avoidance of physical activities, poor skeletal muscle quality, elevated perceived effort with physical tasks, and maintenance of pre-surgical physical activity patterns. Our research laboratory has recently shown that obese patients fear pain induced by physical activity and movement, and this corresponds to lower self-reported physical abilities with tasks related to mobility (e.g., walking, stair climbing, body transfers and recreational activities that involve running, start and stop motions and jumping) $[37,38]$. Despite a paucity of literature addressing the interactions of pain, obesity and joint function over the long term, obese patients can achieve high satisfaction and pain relief and still not increase participation in physical activities at home and in the community. Whether this is due to residual fear of movement and avoidance of activities that may trigger pain is unknown.

Muscle strength rather than muscle mass may be a more clinically relevant determinant of functional status in the older population [39]. Adipose tissue itself contributes to muscle loss through chronic, low grade production of inflammatory cytokines, adipokines and free fatty acids [40]. These chemicals slowly erode muscle mass in the older obese adult, unfavorably shifting the ratio of muscle mass to fat mass. In addition, existing muscles become infiltrated by fat [41], thereby lowering muscle quality and functional ability of the muscle tissue. Residual post-operative strength deficits and fat infiltration may occur in the hip flexors (15\% strength difference compared to non-repaired hip) out to two years [42]; these deficits may contribute to lower functional ability with tasks that activate these muscles. Hence, independent from the improvements in pain and quality of life after a total hip replacement, the obese patient may not achieve the same level of function as non-obese patient in part due to skeletal muscle quality, especially if the patient does not change physical activity patterns to activate loading bearing muscle groups after THA.

The level of perceived difficulty and effort with physical activity is a critical issue for obese individuals, especially those with $\mathrm{BMI} \geq 40 \mathrm{~kg} / \mathrm{m}^{2}$. Morbidly obese patients have poor cardiac, metabolic and ventilatory efficiency and have lower compensatory hyperventilation with exercise [43]. A given exercise workload may require a lot of energy to move heavier limb segments against gravity in the morbidly obese individuals (manifested as lower mechanical efficiency) [44,45]. Self-reported fatigue is higher with increasing BMI [46]. Mobility related tasks, such as short and long distance timed walking tests, stair climb. TUG tests are consistently more challenging and take longer to perform with increasing BMI [47]. Musculoskeletal pain may occur at high intensity activities and may be the limiting factor and not true muscle fatigue [45]. Collectively, the higher perception of muscular effort and discomfort of dyspnea may discourage this population from regularly engaging in physical activities.

While quantitative evidence of physical activity patterns after THA in obese adults is sparse, Donovan et al [48]. reported that patient perceptions of physical activity improved by one year after surgery. A total of $43 \%$ and $9 \%$ of the patients felt that their activity level improved "a lot more" and "a little more" since prior to joint replacement, respectively. The majority of the referenced studies, however, showed that weight gain or maintenance typically occurs after THA, inferring that physical activity levels were not dramatically altered from pre-surgical levels. It has been postulated that with the resolution of hip pain and decreased need for analgesics, normal appetites and caloric intake returned and counteracted any potential effect of increased physical activity in the obese patient [49].

\section{Does weight loss after THA improve long term functional outcomes?}

The assumption that THA would reduce hip pain, and therefore foster increased physical activity and weight loss in the obese patient is not presently substantiated by the limited evidence. In fact, several studies report maintenance of current weight [48] or continued weight gain (ranging from $2.5 \%-3.6 \%$ increase in BMI) one to two years after THA [49-51]. Data suggest that $\geq 75 \%$ of patients experience weight gain over three years [15]. This trend occurs in men and women, irrespective of pre-surgical BMI [50]. However, in one prospective study, the average weight gain by one year was $2.8 \mathrm{~kg}$, with the change occurring primarily in women [52]. In another study, non-obese and obese patients did not lose 
weight, while overweight patients gained a significant amount of weight after surgery [53]. Post-surgical BMI values at follow-up were independent of improvement in mobility using WOMAC score [51] or self-reported improvements in mobility [54]. We surmise that the majority of patients undergoing primary THA will increase their BMI given sufficient follow-up time, irrespective of the outcome [51]. Further investigation of strategies that can be used to encourage perioperative weight loss and slow, safe weight loss after surgery will be important for functional change and preservation of the joint prosthesis lifespan.

\section{Clinical implications}

Obese patients with THA are less functional than nonobese counterparts. If over time the obese patient fails to modify lifestyle, sarcopenic obesity worsens as a spiral of deconditioning and functional dependence develops. The ability to generate muscle strength and power will decline without participation in physical activity. As the obese patient ages and the negative lifestyle behaviors remain, obesity-related comorbidities will worsen. Additional joint pains will develop and the joint implant will ultimately fail earlier in life. Uncontrolled obesity after THA will result in costly and complicated surgical revision procedures. This is a serious issue, because the number of THA performed earlier in obese patients is growing rapidly in the U.S. Possible solutions to this combat this problem include: 1) a strong emphasis on aggressive rehabilitation after THA that focuses on long term maintenance of skeletal muscle quality and mass, and 2) consistent, safe monitored weight loss over the months following the surgery to facilitate physical function and longevity of the joint implant.

\section{Limitations to the evidence}

There are several limitations that deserve comment. First, the determination of "physical function" varied widely across the studies. In this population, there is not yet a standard test battery performed before and after surgery. Second, the reviewed studies typically did not report severity or frequency of other musculoskeletal pain that might be affected by THA. This issue is important, as the hip joint lies centrally to the lower body kinematic chain. Correction of hip pain may improve gait, posture and ambulation, thereby reducing other joint symptoms in the spine and knee. We assume that correction of pain and disability in the hip is the mechanism underlying functional improvement, particularly in obese patients, but we are neglecting to address whether THA has wider reaching effects on overall joint mechanics and pain symptoms.

A substantial attrition rate occurred in many studies. Attrition creates selection bias of the population, and in many studies it was not clear how missing data were handled. In some cases, only completers were included in the analysis. Interpretation of long term results is confounded by the likelihood of selection bias. The lack of emphasis on clinical importance has led to misconceptions and disagreements about the interpretation of the results of clinical trials and a tendency to equate statistical significance with clinical importance. In some instances, statistically significant results may not be clinically important and, conversely, statistically insignificant results do not completely rule out the possibility of clinically important effects [55].

\section{Future directions}

The National Health and Nutrition Examination Survey III data show that lower body functional impairment is becoming more prevalent in obese individuals; among obese persons, $36.8 \%$ reported disability in 1994, whereas $42.2 \%$ reported disability and functional impairment in 2004 [56]. Development of a battery of functional tests of hip flexibility, muscle testing and mobility should be standard practice for THA research to help predict functional success of the surgery. A comprehensive pain and fear assessment will help determine how systemic pain relates to the symptoms and changes in the hip joint. Prospective biomechanical assessments of lower body kinematics in the surgical and non-surgical limb would be very useful in tracking the long term joint motion and physical capabilities. Psychiatric [57], psychosocial [58] and behavioral traits [59] or genetic phenotypes [60] associated with severe obesity should be factors to track in future outcomes studies. There is a dire need for identification of specific exercise, psychosocial, pain management and nutritional interventions that effectively enhance gains made in physical function over the long term. Finally, it would be clinically important to determine what amount of weight loss maximizes implant lifespan.

\section{Conclusions}

THA confers significant pain reduction and improvement in quality of life irrespective of BMI. While functional improvement occurs after THA, available evidence indicates that obese patients are less likely to attain the same level of physical function over the long term. Uncontrolled obesity is related to worsening of comorbidities and excessive health care costs over the long term. Aggressive and sustainable rehabilitation strategies that include physical exercise, psychosocial components and behavior modification may be highly useful in maximizing and maintaining weight loss after THA. Furthermore, this type of rehabilitation may also reduce the overall health care burden. 


\section{Competing interests}

The authors declare that they have no competing interests.

\section{Authors' contributions}

$\mathrm{HV}$ primary writer. MBH text contributor, editing. PFG text contributor, editing. RV text contributor, editing. ANS collection of scientific papers, text contributor. BPC text contributor, editing. KRV text contributor, editing. All authors read and approved the final manuscript.

\section{Acknowledgements}

This work has been supported by the University of Florida's Interdisciplinary Center for Musculoskeletal Training and Research, Department of Orthopaedics and Rehabilitation.

Received: 9 March 2011 Accepted: 2 April 2012

Published: 25 April 2012

\section{References}

1. Bourne R, Mukhi S, Zhu N, Keresteci M, Marin M: Role of obesity on the risk for total hip or knee arthroplasty. Clinical Orthopedics and Related Research 2007, 465:185-188.

2. Braeken AM, Lochhaas-Gerlach JA, Gollish JD, Myles JD, Mackenzie TA: Determinants of 6-12 month postoperative functional status and pain after elective total hip replacement. International Journal of Quality of Health Care 1997, 9(6):413-418.

3. Busato A, Röder C, Herren S, Eggli S: Influence of high BMI on functional outcome after total hip arthroplasty. Obes Surg 2008, 18(5):595-600.

4. American A, of, Orthopaeic Surgeons(2011) Total Hip Replacement. http:// orthoinfo.aaos.org/topic.cfm?topic=A00377. Accessed January 14, 20112011 (Last reviewed and updated: April 2009)

5. Singh JA, Lewallen DG: Predictors of activity limitation and dependence on walking aids after primary total hip arthroplasty. Journal of the American Geriatric Society 2010, 58(12):2387-2393.

6. Chee YH, Teoh KH, Sabnis BM, Ballantyne JA, Brenkel IJ: Total hip replacement in morbidly obese patients with osteoarthritis: results of a prospectively matched study. Journal of Bone and Joint Surgery British Volume 2010, 92(8):1066-1071.

7. Le Duff MJ, Amstutz HC, Dorey FJ: Metal-on-metal hip resurfacing for obese patients. Journal of Bone and Joint Surgery American Volume 2007, 89 (12):2705-2711.

8. Lübbeke A, Stern R, Garavaglia G, Zurcher L, Hoffmeyer P: Differences in outcomes of obese women and men undergoing primary total hip arthroplasty. Arthritis and Rheumatism 2007, 57(2):327-334.

9. Villareal DT, Apovian CM, Kushner RF, Klein S: American society for nutrition; NAASO TOS. Obesity in older adults: technical review and position statement of the American Society for Nutrition and NAASO, The Obesity Society. Obes Res 2005, 13(11):1849-1863.

10. Grundy SM, Brewer HBJ, Cleeman JI, Smith SCJ, Lenfant C, American H: Association, National, Heart, Lung, and, Blood, Institute. Definition of metabolic syndrome: Report of the National Heart, Lung, and Blood Institute/American Heart Association conference on scientific issues related to definition. Circulation 2004, 109(3):433-438.

11. McLaughlin JR, Lee KR: The outcome of total hip replacement in obese and non-obese patients at 10-to 18-years. Journal of Bone and Joint Surgery American Volume 2006, 88-B(10):1286-1292.

12. Singh JA, Lewallen D: Age, gender, obesity, and depression are associated with patient-related pain and function outcome after revision total hip arthroplasty. Clinics in Rheumatology 2009, 28(12):1419-1430.

13. Stickles B, Phillips L, Brox WT, Owens B, Lanzer WL: Defining the relationship between obesity and total joint arthroplasty. Obes Res 2001 9(3):219-223.

14. Haverkamp D, de Man FH, de Jong PT, van Stralen RA, Marti RK: Is the long-term outcome of cemented THA jeopardized by patients being overweight? Clinical Orthopedics and Related Research 2008, 466(5):1162-1168.

15. Aderinto J, Brenkel IJ, Chan P: Weight change following total hip replacement: a comparison of obese and non-obese patients. Surgeon 2005, 3(4):269-272.

16. Andrew JG, Palan J, Kurup HV, Gibson P, Murray DW, Beard DJ: Obesity in total hip replacement. Journal of Bone and Joint Surgery British Volume 2008, 90(4):424-429.
17. Chan CL, Villar RN: Obesity and quality of life after primary hip arthroplasty. Journal of Bone and Joint Surgery British Volume 1996, 78(1):78-81.

18. Judge A, Cooper C, Williams S, Dreinhoefer K, Dieppe P: Patient-reported outcomes one year after primary hip replacement in a European Collaborative Cohort. Arthritis Care Research (Hoboken) 2010, 62(4): 480-488.

19. Moran M, Walmsley P, Gray A, Brenkel IJ: Does body mass index affect the early outcome of primary total hip arthroplasty? J Arthroplast 2005, 20 (7):866-869.

20. Søballe K, Christensen F, Luxhøj T: Hip replacement in obese patients. Acta Orthopaedica Scandinavica 1987, 58(3):223-225.

21. Gandhi R, Razak F, Mahomed NN: Ethnic differences in the relationship between obesity and joint pain and function in a joint arthroplasty population. J Rheumatol 2008, 35:1874-1877.

22. Naylor JM, Harmer AR, Heard RC: Severe other joint disease and obesity independently influence recovery after joint replacement surgery: an observational study. Austrian Journal of Physiotherapy 2008, 54(1):57-64.

23. Jackson MP, Sexton SA, Yeung E, Walter WL, Walter WK, Zicat BA: The effect of obesity on the mid-term survival and clinical outcome of cementless total hip replacement. Journal of Bone and Joint Surgery British Volume 2009, 91(10):1296-1300.

24. Yeung E, Jackson M, Sexton S, Walter W, Zicat B, Walter W (2010) The effect of obesity on the outcome of hip and knee arthroplasty. International Orthopedics. May 29 epub ahead of print

25. Dowsey MM, Choong PF: Early outcomes and complications following joint arthroplasty in obese patients: a review of the published reports. ANZ J Surg 2008, 78(6):439-444.

26. Gandhi R, Razak F, Davey JR, Mahomed NN: Metabolic syndrome and the functional outcomes of hip and knee arthroplasty. J Rheumatol 2010, 37 (9):1917-1922.

27. Lübbeke A, Kampfen S, Stern R, Hoffmeyer P: Results of surgical repair of abductor avulsion after primary total hip arthroplasty. J Arthroplast 2008, 23(5):694-698.

28. Lübbeke A, Katz JN, Perneger TV, Hoffmeyer P: Primary and revision hip arthroplasty: 5-year outcomes and influence of age and comorbidity. J Rheumatol 2007, 34(2):394-400.

29. Dowsey MM, Liew D, Stoney JD, Choong PF: The impact of obesity on weight change and outcomes at 12 months in patients undergoing total hip arthroplasty. Medical Journal of Austria 2010, 193(1):17-21.

30. Lübbeke A, Moons KG, Garavaglia G, Hoffmeyer P: Outcomes of obese and nonobese patients undergoing revision total hip arthroplasty. Arthritis and Rheumatism 2008, 59(5):738-745.

31. Lübbeke A, Garavaglia G, Barea C, Roussos C, Stern R, Hoffmeyer P: Influence of obesity on femoral osteolysis five and ten years following total hip arthroplasty. Journal of Bone and Joint Surgery American Volume 2010, 92(10):1964-1972.

32. Gandhi R, Razak F, Davey JR, Rampersaud YR, Mahomed NN: Effect of sex and living arrangement on the timing and outcome of joint replacement surgery. Can J Surg 2010, 53(1):37-41.

33. McLaughlin JR, Lee KR: The outcome of total hip replacement in obese and non-obese patients at 10- to 18-years. Journal of Bone and Joint Surgery, British volume 2006, 88(10):1286-1292.

34. Naylor JM, Harmer AR, Heard RC: Severe other joint disease and obesity independently influence recovery after joint replacement surgery: an observational study. Australian Journal of Physiotherapy 2008, 54(1):57-64.

35. Stickles B, Phillips L, Brox WT, Owens B, Lanzer WL: Defining the relationship between obesity and total joint arthroplasty. Obesity $R$ 2001, 9(3):219-223.

36. Charnely J: The long-term results of low-friction arthroplasty of the hip performed as a primary intervention. Journal of Bone and Joint Surgery British Volume 1972, 54(1):61-76.

37. Vincent HK, Lamb KM, Day TI, Tillman SM, Vincent KR, George SZ: Morbid obesity is associated with fear of movement and lower quality of life in patients with knee pain-related diagnoses. PM\&R 2010, 2 (8):713-722.

38. Vincent HK, Omli MR, Day TI, Hodges M, Vincent K, R., George SZ (2011) Fear of movement, quality of life and self-reported disability in obese patients with chronic lumbar pain. Pain Medicine. In press

39. Stenholm S, Harris TB, Rantanen T, Visser M, Kritchevsky SB, Ferrucci L: Sarcopenic obesity: definition, cause and consequences. Current Opinions in Clinical Nutrition and Metabolism Care 2008, 11(6):693-700. 
40. Jensen G, Hsiao PY: Obesity in older adults: relationship to functional limitation. Current Opinion in Clinical Nutrition and Metabolic Care 2010, 13 (1):46-51.

41. Goodpaster BH, Stenger VA, Boada F, et al: Skeletal muscle lipid concentration quantified by magnetic resonance imaging. Am J Clin Nutr 2004, 79(5):748-754.

42. Rasch A, Dalén N, Berg HE: Muscle strength, gait, and balance in 20 patients with hip osteoarthritis followed for 2 years after THA. Acta Orthopedics 2010, 81(2):183-188.

43. Zavorsky GS, Murias JM, Kim do J, Gow J, Christou NV: Poor compensatory hyperventilation in morbidly obese women at peak exercise. Respiration Physiologya nd Neurobiology 2007, 159:187-195.

44. Ofir D, Laveneziana P, Webb KA, O'Donnell DE: Ventilatory and perceptual responses to cycle exercise in obese women. J Appl Physiol 2007 102:2217-2226.

45. Hulens M, Vansant G, Lysens R, Claessens AL, Muls E: Exercise capacity in lean versus obese women. Scandinavian Journal of Medicine and Sport Science 2001, 11(5):305-309.

46. Sartorio A, Fontana P, Trecate L, Lafortuna CL: Short-term changes of fatigability and muscle performance in severe obese patients after an integrated body mass reduction program. Diabetes Nutrition and Metabolism 2003, 16(2):88-93.

47. Vincent HK, Vincent KR, Lamb KM: Obesity and mobility disability in the older adult. Obes Rev 2010, 11(8):568-579.

48. Donovan J, Dingwall I, McChesney S: Weight change 1 year following total knee or hip arthroplasty. ANZ J Surg 2006, 76(4):222-225.

49. Abu-Rajab RB, Findlay H, Young D, Jones B, Ingram R: Weight changes following lower limb arthroplasty: a prospective observational study. Scottish Medical Journal 2009, 54(1):26-28.

50. Middleton FR, Boardman DR: Total hip arthroplasty does not aid weight loss. Ann R Coll Surg Engl 2007, 89(3):288-291.

51. Jain SA, Roach RT, Travlos J: Changes in body mass index following primary elective total hip arthroplasty. Correlation with outcome at 2 years. Acta Orthopedics Belgium 2003, 69(5):421-425.

52. Woodruff MJ, Stone MH: Comparison of weight changes after total hip or knee arthroplasty. J Arthroplast 2001, 16(1):22-24.

53. Heisel C, Silva M, dela Rosa MA, Schmalzried TP: The effects of lowerextremity total joint replacement for arthritis on obesity. Orthopedics 2005, 28(2):157-159.

54. Woolf VJ, Charnley GJ, Goddard NJ: Weight changes after total hip arthroplasty. J Arthroplast 1994, 9(4):389-391.

55. Stolberg HO, Norman G, Trop I: Randomized controlled trials. Am J Roentgenol 2004, 183:1539-1544.

56. Alley DE, Chang WW: The changing relationship of obesity and disability, 1988-2004. JAMA 2007, 298(17):2020-2027.

57. Marchesini G, Bellini M, Natale $S$, et al: Psychiatric distress and health-related quality of life in obesity. Diabetes, Nutrition and Metabolism 2003, 16(3):145-154

58. Marcus DA: Obesity and the impact of chronic pain. Clinical Journal of Pain 2004, 20(3):186-191.

59. Lykouras L: Psychological profile of obese patients. Dig Dis 2008, 21(6):36-39.

60. Ortega-Alonso A, Sipilä S, Kujala UM, Kaprio J, Rantanen T (2009) Genetic influences on adult BMI followed over 29 years and their effects on late life mobility: a study of twin sisters. Journal of Epidemiology and Community Health. Mar 19 epub ahead of print

doi:10.1186/1749-799X-7-16

Cite this article as: Vincent et al:: Obesity and long term functional outcomes following elective total hip replacement. Journal of Orthopaedic Surgery and Research 2012 7:16.

\section{Submit your next manuscript to BioMed Central and take full advantage of:}

- Convenient online submission

- Thorough peer review

- No space constraints or color figure charges

- Immediate publication on acceptance

- Inclusion in PubMed, CAS, Scopus and Google Scholar

- Research which is freely available for redistribution

Submit your manuscript at www.biomedcentral.com/submit 